\title{
Mildly symptomatic liraglutide-induced acute pancreatitis in a patient with type 2 diabetes mellitus: a case report
}

\author{
Mohammed Ali Gameil $^{1 *}$ and Ahmed Hassan Elsebaie ${ }^{2}$ [D
}

\begin{abstract}
Background: Acute pancreatitis (AP) represents a serious clinical challenge as it can threaten the patient's life if it is missed or improperly managed. Liraglutide is one of the glucagon-like peptide 1 receptor agonists (GLP1-RA) which represent a novel class of antidiabetic medications in the Egyptian market. Hereby, we report a case of liraglutideinduced acute pancreatitis with atypical presentation.
\end{abstract}

Case presentation: A 53-year-old Egyptian male patient with diabetes presented to the emergency department with abdominal discomfort and vomiting without significant abdominal pain. Serum lipase and amylase were elevated more than three folds the upper normal limit (NUL 300 and $110 \mathrm{U} / \mathrm{L}$ respectively); abdominal ultrasonography was inconclusive, but contrast-enhanced computed tomography was diagnostic. A diagnosis of liraglutide-induced AP was built after exclusion of other causes. After admission, his medications were modified and improved clinically after 1 week.

Conclusion: Mildly symptomatic AP in diabetic patients is a clinical challenge as it can be missed. Therefore, in certain clinical situations, AP should be suspected in patients administrating liraglutide particularly for those with autonomic neuropathy.

Keywords: Liraglutide, Acute pancreatitis, Type 2 diabetes mellitus, Case report

\section{Background}

Acute pancreatitis (AP) is conventionally diagnosed by the presence of two of the three following criteria: characteristic abdominal pain, elevated serum amylase and/ or lipase more than three folds the upper normal limit, and characteristic abdominal imaging findings [1]. Gallstones and alcohol are the leading causes of AP; however, other causes such as hypertriglyceridemia, hyper/ hypocalcemia, autoimmune, infection, neoplasm, genetics, trauma, endoscopic retrograde cholangiopancreatography (ERCP), and drug-induced pancreatitis (DIP) are increasingly recognized. More than 500 drugs were

\footnotetext{
*Correspondence: drmaligameil1979@yahoo.com

'Endocrinology Unite, Internal Medicine Department, Faculty of Medicine,

Mansoura University, Dakahlia, Mansoura, Egypt

Full list of author information is available at the end of the article
}

reported to induce AP [2]; hereby, we report a case of DIP with atypical presentation.

\section{Case presentation}

A male patient 53 years old experienced mild abdominal discomfort and repeated vomiting for 1 week before admission with gradual onset and progressive course preceded by nausea, anorexia, excess flatus, and chronic constipation (1-2 times/week). He had type 2 diabetes mellitus (T2D) and hypertension ( 8 and 2 years ago respectively), with no history of fever, alcohol consumption, or drug intake rather than his daily medications that included insulin degludec $26 \mathrm{U}$ OD, liraglutide 1.8 $\mathrm{mg}$ OD, metformin $500 \mathrm{mg}$ BID for T2D, and lisinopril $10 \mathrm{mg}$ OD for hypertension, and no past history of infectious diseases, blood transfusion, surgery, ICU

\section{Springer Open}

๑ The Author(s). 2020 Open Access This article is licensed under a Creative Commons Attribution 4.0 International License, which permits use, sharing, adaptation, distribution and reproduction in any medium or format, as long as you give appropriate credit to the original author(s) and the source, provide a link to the Creative Commons licence, and indicate if changes were made. The images or other third party material in this article are included in the article's Creative Commons licence, unless indicated otherwise in a credit line to the material. If material is not included in the article's Creative Commons licence and your intended use is not permitted by statutory regulation or exceeds the permitted use, you will need to obtain permission directly from the copyright holder. To view a copy of this licence, visit http://creativecommons.org/licenses/by/4.0/. 
admission, or alcohol consumption with irrelevant family history.

Physical examination showed body weight $108 \mathrm{~kg}$, BMI $34.5 \mathrm{~kg} / \mathrm{m}^{2}$, waist circumference $124 \mathrm{~cm}$, positive acanthosis nigricans sign, ABP 130/75 mmHg, pulse $105 / \mathrm{min}$, temperature $38.2{ }^{\circ} \mathrm{C}$, and respiratory rate $20 /$ min. Abdominal examination showed marked diffuse abdominal distension with epigastric tenderness on palpation and negative shifting dullness sign. Chest and heart examination showed no abnormal signs. The right foot showed a small uncomplicated pressure ulcer.

Laboratory tests are done as shown in Table 1. Abdominal ultrasonography (US) revealed excess colonic gas, sluggish bowel motion, no gall bladder ( GB) stones

Table 1 Laboratory parameters of the patient before and throughout acute pancreatitis

\begin{tabular}{|c|c|c|c|c|}
\hline Parameter & 3 months before & Day 0 in ER & 3rd day & 8th day \\
\hline Lipase (U/L) & 74 & 1880 & 867 & 290 \\
\hline Amylase (U/L) & 66 & 1060 & 450 & 124 \\
\hline ESR $(\mathrm{mm} / \mathrm{h})$ & 10 & 75 & 45 & 23 \\
\hline CRP (mg/L) & 6 & 124 & 37 & 10 \\
\hline Creatinine $(\mathrm{mg} / \mathrm{dL})$ & 1 & 1.4 & 1.2 & 1.12 \\
\hline BUN (mg/dL) & 16 & 20 & 18 & 18 \\
\hline Calcium (mg/dL) & 8.9 & 10.1 & 9.15 & 9.45 \\
\hline Phosphorus (mg/dL) & 4.1 & 4.51 & 4.35 & 4.2 \\
\hline Magnesium (mg/dL) & 2.1 & 2.15 & 2.19 & 2.2 \\
\hline Ferritin (ng/ml) & 42 & 90 & 75 & 70 \\
\hline ALT (IU/L) & 36 & 100 & 73 & 47 \\
\hline AST (IU/L) & 28 & 71 & 36 & 22 \\
\hline GGT (IU/L) & 44 & 119 & 81 & 51 \\
\hline Albumin (g/dL) & 4.6 & 4.5 & 4.6 & 4.6 \\
\hline Alkaline phosphatase (IU/L) & 36 & 58 & 38 & 38 \\
\hline Total bilirubin (mg/dL) & 1.1 & 1.2 & 1 & 1.1 \\
\hline \multicolumn{5}{|l|}{ Lipid profile (mg/dL) } \\
\hline $\mathrm{TC}$ & 132 & 199 & 187 & 156 \\
\hline TG & 144 & 146 & 131 & 145 \\
\hline HDL-C & 47 & 46 & 35 & 50 \\
\hline LDL-C & 57 & 124 & 126 & 67 \\
\hline VLDL-C & 29 & 29 & 26 & 29 \\
\hline WBCs $\left(\times 10^{3}\right)$ & 7.9 & 16.3 & 7.9 & 7.4 \\
\hline $\operatorname{RBCs}\left(\times 10^{6}\right)$ & 4.69 & 4.59 & 4.46 & 4.75 \\
\hline $\mathrm{HB}(\mathrm{g} / \mathrm{dL})$ & 13.6 & 13.3 & 13.4 & 13.1 \\
\hline Hct (\%) & 40.3 & 40.4 & 38.7 & 41.5 \\
\hline MCV (fL) & 85.9 & 88 & 86.8 & 87.4 \\
\hline $\mathrm{MCH}(\mathrm{pg})$ & 29 & 29 & 30 & 27.6 \\
\hline $\mathrm{MCHC}(\mathrm{g} / \mathrm{dL})$ & 33.7 & 32.9 & 34.6 & 31.5 \\
\hline RDW (\%) & 12.8 & 13 & 13.1 & 13.3 \\
\hline PLT $\left(\times 10^{3}\right)$ & 350 & 320 & 306 & 336 \\
\hline MPV (fL) & 8.2 & 8.1 & 8.4 & 7.9 \\
\hline Segment (\%) & 55.8 & 53.3 & 53.4 & 53.4 \\
\hline Lymphocyte (\%) & 23 & 29.9 & 30.3 & 31.4 \\
\hline Monocyte (\%) & 10.6 & 10.3 & 10.1 & 9.2 \\
\hline Eosinophil (\%) & 9.4 & 5.7 & 5 & 5 \\
\hline Basophil (\%) & 1.2 & 0.8 & 1.2 & 1 \\
\hline
\end{tabular}


or dilated intrahepatic biliary radicles (IHBR), homogenous bright liver parenchyma and normal kidneys with difficult visualization of the pancreas, and no ascites or lymphadenopathy. The provisional diagnosis was acute pancreatitis, but it was uncertain due to the absence of the characteristic pain and inconclusive abdominal US. Multiphasic contrast-enhanced computed tomography (CECT) of the abdomen was done and revealed a diffuse enlarged pancreas with heterogeneous enhancement of the parenchyma, irregular contour with peripancreatic edema, and fat strands. There were no necrotic signs, abnormal fluid collection, pseudocyst, or mass. CT severity index (CTSI) score was 2. A diagnosis of liraglutide-induced acute pancreatitis was built.

Three months prior to the attack, the patient was on oral antidiabetic drugs (glimepride $6 \mathrm{mg}$ OD and vildagliptin/metformin 50/1000 BID) with HBA1c that was 9.23\% out of target complicated with right foot neuropathic ulcer and diabetic gastroparesis symptoms such as chronic constipation and persistent fullness. The treatment was modified to basal insulin degludec $10 \mathrm{IU}$ with gradual up-titrated dose according to the fasting plasma glucose till reaching $26 \mathrm{U}$ OD plus GLP1-RA (liraglutide) with gradual up-titrated dose from $0.6,1.2$, to $1.8 \mathrm{mg}$ OD added on metformin $500 \mathrm{mg}$ BID according to the American Diabetes Association guidelines (ADA 2020) [3]. Prior to liraglutide initiation, the patient was secured against GLP1-RA contraindication such as a history of liraglutide allergy, pancreatitis or pancreatic cancer, medullary thyroid carcinoma (MTC), or multiple endocrine neoplasia (MEN) 2 in the patient or his family. Improved self-monitoring blood glucose (SMBG) readings and lowered HBA1c to $7.71 \%$ with weight loss of $2.7 \mathrm{~kg}$ over the last 3 months were noticed.

After admission, the patient started soft enteral feeding, prophylactic antibiotic with basal-bolus insulin regimen of insulin degludec and insulin aspart with frequent assessment of serum plasma glucose, electrolytes, and arterial blood gases.

After 3 days, the patient exhibited slight improvement of serum lipase, amylase, and inflammatory markers with the abdominal US that showed a moderate colonic distension with a slight improvement of the bowel motion without pain on probing. Five days later, CECT was repeated and showed essentially normal pancreatic status with improved laboratory findings (Table 1). Our patient had liraglutide-induced mildly symptomatic acute pancreatitis. The most challenging risk was the absence of significant pain which represents an alarming symptom.

\section{Discussion}

Despite the proven safety and efficacy in the management of T2D, GLP1-RA have been associated with AP particularly exenatide and to lesser frequency liraglutide
[4]. The majority of patients exhibited a mild self-limited disease, but about $20 \%$ may have moderate to severe AP. Traditionally, accurate history taking and pancreatic amylase, lipase, and inflammatory markers in addition to the abdominal US are the pillars of AP diagnosis; however, CECT is required only if the diagnosis is uncertain [5]. Many scores are traditionally used to detect the severity and prognosis of AP such as Ranson criteria (1974), Glasgow-Imrie score (1978), Acute Physiology and Chronic Health Evaluation II (APACHE II), Simplified Acute Physiology Score (SAPS II) (1984), Sequential Organ Failure Assessment (SOFA), CT severity index (CTSI), Bedside Index of Severity in Acute Pancreatitis (BISAP) score (2008), and Japanese Severity Score [6].

Our patient experienced liraglutide-induced AP without the characteristic pain pattern that may be attributed to diabetic autonomic neuropathy. The absence of pain represents a serious clinical challenge with probable missed diagnosis of AP. Funch et al. [7] found that liraglutide was not associated with an increased risk of AP, but they reported concerns regarding the limited numbers, rarity of outcomes, and unmeasured confounding factors and ethnicity issue. The US Food and Drug Administration (FDA) and European Medicine Agency reviewed the existing data about GLP1-RA, and till now, they did not get a final conclusion regarding a causal relationship between GLP1-RA and AP; therefore, they keep safety risks for these drugs. Both agencies called for more research on this issue [8]. Clinical trials of liraglutide revealed more cases of AP in the liraglutide arms than the control arms. However, the Liraglutide Effect and Action in Diabetes: Evaluation of Cardiovascular Outcome Results (LEADER) trial and the recent metaanalyses did not consider AP as a major adverse effect of liraglutide $[9,10]$.

\section{Conclusion}

Acute pancreatitis represents a potential complication of liraglutide. Therefore, in certain clinical situations, assessment of pancreatic enzymes for patients administrating liraglutide is required to avoid missed diagnosis and subsequent serious complications of AP that may threaten patients' lives particularly in diabetic patients with autonomic neuropathy.

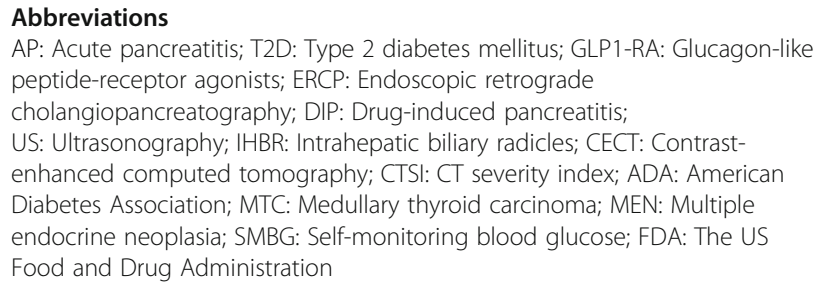

Acknowledgements

Not applicable 


\section{Authors' contributions}

Author 1 "M.A.G" carried out the conception and literature review, analyzed and interpreted the patient's data, and wrote the final manuscript. Author 2 "A.H.E" contributed in the laboratory work and critical revision of the draft and shared in the final manuscript writing. The authors read and approved the final manuscript.

\section{Funding \\ By author}

\section{Availability of data and materials}

Available.

\section{Ethics approval and consent to participate}

Written informed consent was obtained from the patient for publication of this case report and accompanying data. It was approved by the Institutional Review Board for Clinical Research committee of Mansoura University. All procedures were in accordance with the ethical standards of the institutional research committee and with the 1964 Helsinki Declaration and its later amendments or comparable ethical standards.

\section{Consent for publication}

Written consent to publish was obtained from the patient prior to submission and is available.

\section{Competing interests}

None

\section{Author details}

${ }^{1}$ Endocrinology Unite, Internal Medicine Department, Faculty of Medicine, Mansoura University, Dakahlia, Mansoura, Egypt. ${ }^{2}$ Clinical Pathology Department, Faculty of Medicine, Mansoura University, Dakahlia, Mansoura, Egypt.

Received: 1 October 2020 Accepted: 2 November 2020

Published online: 11 November 2020

\section{References}

1. Garber A, Frakes C, Arora Z, Chahal P (2018) Mechanisms and management of acute pancreatitis. Gastroenterol Res Pract 2018:6218798. https://doi.org/ 10.1155/2018/6218798. eCollection 2018

2. Hung WY, Abreu Lanfranco O (2014) Contemporary review of drug-induced pancreatitis: a different perspective. World I Gastrointest Pathophysiol 5: 405-415. [PMC free article] [PubMed] [Google Scholar]

3. Joshua J. Neumiller, George Bakris, M, William T. Cefalu, Jill Crandall, David D'Alessio, Jennifer Green, et al (2020) Pharmacologic approach to glycemic management: Standard of Medical Care in Diabetes-2020 American Diabetes Association. Diabetes Care 43(Supplement 1): S98-S110.https://doi. org/10.2337/dc20-S009.

4. Alves C, Batel-Marques F, Macedo AF (2012) A meta-analysis of serious adverse events reported with exenatide and liraglutide: acute pancreatitis and cancer. Diabetes Res Clin Pract 98:271-284. [PubMed] [Google Scholar]

5. van Dijk SM, Hallensleben NDL, van Santvoort HC et al (2017) Acute pancreatitis: recent advances through randomised trials. Gut 66:2024-2032

6. Gurusamy KS, Debray TPA, Rompianesi G (2018) Prognostic models for predicting the severity and mortality in people with acute pancreatitis. Cochrane Database Syst Rev 2018, Issue 5. Art. No.: CD013026. https://doi. org/10.1002/14651858.CD013026.

7. Donnie Funch, , Kathleen Mortimer, Najat J. Ziyadeh, John D. Seeger, Ling Li, Heather Norman, et al (2019) Liraglutide use and evaluation of pancreatic outcomes in a US commercially insured population. Diabetes Obes Metab 21(8): 1837-1848.Published online 2019 May 24. https://doi.org/10.1111/ dom.13739

8. Amy G Egan, Eberhard Blind, Kristina Dunder, Pieter A de Graeff, B Timothy Hummer, Todd Bourcier, et al. (2014) Pancreatic safety of incretin-based drugs-FDA and EMA assessment. N Engl J Med 370:794-796. [PubMed] [Google Scholar]

9. Steinberg WM, Buse JB, Ghorbani MLM, Ørsted DD, Nauck MA and the LEADER Steering Committee on behalf of LEADER Trial Investigators (2017) Amylase, lipase, and acute pancreatitis in people with type 2 diabetes treated with liraglutide: results from the LEADER randomized trial. Diabetes Care 40:966-972. [PubMed] [Google Scholar]

10. Giorda CB, Sacerdote C, Nada E, Marafetti L, Baldi I, Gnavi R (2015) Incretinbased therapies and acute pancreatitis risk: a systematic review and metaanalysis of observational studies. Endocrine 48:461-471. [PubMed] [Google Scholar]

\section{Publisher's Note}

Springer Nature remains neutral with regard to jurisdictional claims in published maps and institutional affiliations.

\section{Submit your manuscript to a SpringerOpen ${ }^{\circ}$ journal and benefit from:}

- Convenient online submission

- Rigorous peer review

- Open access: articles freely available online

High visibility within the field

- Retaining the copyright to your article

Submit your next manuscript at $\boldsymbol{\nabla}$ springeropen.com 